\section{TÀI LIẸU THAM KHẢO}

1. Hemphill, J.C., 3rd, et al., Guidelines for the Management of Spontaneous Intracerebral Hemorrhage: A Guideline for Healthcare Professionals From the American Heart Association/American Stroke Association. Stroke, 2015. 46(7): p. 2032-60.

2. Connolly, E.S., Jr., et al., Guidelines for the management of aneurysmal subarachnoid hemorrhage: a guideline for healthcare professionals from the American Heart Association/american Stroke Association. Stroke, 2012. 43(6): p. 1711-37.

3. Frontera, J.A., et al., Prediction of symptomatic vasospasm after subarachnoid hemorrhage: the modified fisher scale. Neurosurgery, 2006. 59(1): p. 21-7; discussion 21-7.

4. Etminan, $\mathbf{N}_{\text {., }}$ et al., Worldwide Incidence of Aneurysmal Subarachnoid Hemorrhage According to Region, Time Period, Blood Pressure, and Smoking Prevalence in the Population: A Systematic Review and Meta-analysis. JAMA Neurol, 2019. 76(5): p. 588-597.

5. Katsuno, M., et al., Subarachnoid hemorrhage caused by ruptured posterior inferior cerebellar artery aneurysm arising from the extracranial portion of an anomalous vertebral artery. Neurol Med Chir (Tokyo), 2012. 52(7): p. 499-501.

6. Togha, M., et al., Warning signs and symptoms of subarachnoid hemorrhage. South Med J, 2009. 102(1): p. 21-4

7. Kaminogo, M., M. Yonekura, and S. Shibata, Incidence and outcome of multiple intracranial aneurysms in a defined population. Stroke, 2003. 34(1): p. 16-21.

8. Yao, Z, et al., Timing of surgery for aneurysmal subarachnoid hemorrhage: A systematic review and meta-analysis. Int J Surg, 2017. 48: p. 266-274.

\title{
SỰ BộC Lộ THỤ THỂ ANDROGEN VÀ ESTROGEN TRONG UNG THƯ BIỂU MÔ TUYẾN VÚ XÂM NHẬP
}

\section{TÓM TẮT}

Thu thể androgen (AR) liên quan tới môt yếu tố phiên mã kiểm soát các gen đặc hiệu liên quan đến các quá trình tế bào khác nhau, đôi khi ngước lai: nó có thể kích thích hoặc ức chế cả tăng sinh tế bào và apoptosis, tùy thuộc vào các con đường tín hiêuu đồng thời được hoạt hóa. Mục tiêu: Nhận xét một số mối liên quan giữa sự bộc lộ $A R, E R$ với typ phân tử, NPI, nhóm nguy cơ và giai đoạn sau mổ của ung thư vú. Đối tượng và phương pháp nghiên cứu: Mẫu mô u čủa 94 bệnh nhân ung thư vú được nhuộm hóa mô miễn dịch với dấu ấn $A R$, ER để xác định kiểu hình miê̂n dịch và đánh giá mối liên quan với một số đặc điểm GPB. Kết quả nghiên cứu: Ở typ phân tử HER2, nhóm AR-ER- chiếm tỷ lệ cao nhất $(55,9 \%)$ và ung thư vú dang đáy, kiểu hình $A R+E R-$ chiếm tỷ lê phổ biến nhất là $52,9 \%$. AR-ER- chiếm tỷ lệ cao nhất ở ung thư vú nguy cơ xấu (58,8\%). Ung thư vú giai đoan I nhóm $A R-E R+$ và $A R+E R+$ đều chiếm tỷ lệ cao hơn giai đoạn III (lần lượt là 40,0 vs $13,3 \%$ và 29,8 vs 21,5\%). Kết luân: Kiểu hình miễn dịch AR-ERthường kết hợp với các đặc trưng GPB xấu nhất.

Tư khóa: Thu thể androgen, Thu thể estrogen, Ung thư vú.

\section{SUMMARY \\ EXPRESSION OF ANDROGEN AND ESTROGEN RECEPTORS IN INVASIVE}

\footnotetext{
*Bênh viên $K$

Chịu trách nhiệm chính: Nguyễn Văn Chủ

Email: chunv.nch@gmail.com

Ngày nhận bài: 1.2.2021

Ngày phản biên khoa hoc: 16.3.2021

Ngày duyệt bài: 23.3.2021
}

Nguyễn Văn Chủ*

\section{BREAST CARCINOMA}

Androgen receptor (AR) links a transcription factor that controls specific genes involved in different, sometimes opposite, cellular processes: it can stimulate or suppress both cell proliferation and apoptosis, depending on the concurrent signaling pathways activated. Purpose: To Comment on some relationships between the expression of $A R, E R$ and molecular type, NPI, risk group and postoperative stage of breast cancer. Methods: Tumor samples of 94 breast cancer patients were stained with AR and ER IHC markers to determine the immunophenotype and to assess association with some pathological features. Results: In the HER2 molecular type, the AR-ER- group was accounted for the highest proportion (55.9\%) and in the breast cancer with basal type, phenotype AR+ ER- was accounted for the most common rate of $52.9 \%$. AR-ER- accounts for the highest incidence of bad risk breast cancer (58.8\%). Both AR-ER+ and AR+ ER+ stage I breast cancer were accounted for a higher rate than stage III (40.0 vs $13.3 \%$ and 29.8 vs $21.5 \%$, respectively). Conclusion: The AR-ER- immunophenotype is often associated with the worst pathological characteristics.

Key words: Androgen receptor, Estrogen receptor, Breast cancer.

\section{I. ĐặT VẤN ĐỀ}

Thụ thể androgen (AR) là một thụ thể nội tiết tố steroid thuộc đến họ thụ thể nhân cùng với estrogen (ER), glucocorticoid, progesterone (PR) và thu thể mineralcorticoid. Nó liên quan tới một yếu tố phiên mã kiểm soát các gen đặc hiệu liển quan đến các quá trình tế bào khác nhau, đôi khi ngược lại: nó có thể kích thích hoặc ức chế cả 
tăng sinh tế bào và apoptosis, tùy thuộc vào các con đường tín hiệu đồng thời được hoạt hóa [16]. Thụ thể androgen được biểu hiện ở khoảng 70-90\% trường hợp ung thư vú [1].

Trong ung thư vú dương tính với $E R, A R$ đã được chứng minh là can thiệp vào sự phiên mã phụ thuộc ER thông qua cạnh tranh với ER cho các vị trí liên kết tại các yếu tố đáp ứng estrogen (EREs) hoặc thông qua cạnh tranh cho các bộ đồng điều chế phiên mã [1]. Thật vậy, tỉ lệ bộc lộ $A R$ / ER xác định sự tác động của cả hai AR và ER trong điều hòa sự tăng sinh tế bào ung thư vú. Khi nào mức đô biểu hiên của $A R$ cao hơn so với $E R, A R$ liên kết với $E R E S$, do đó có tác dụng ức chế tế bào sự phát triển. Ngược lại, nếu $E R$ cao hơn $A R$, sau đó $E R$ liên kết với yếu tố đáp ứng androgen (ARE), dẫn đến tăng sinh tế bào $[2,3-5]$.

Ở Việt Nam, đã có nhiều công trình nghiên cứu về bệnh ung thư vú cả về hình thái $\mathrm{MBH}$ lẫn $\mathrm{HMMD}$, tuy nhiên chưa có nghiên cứu nào về sự bộc lộ của thụ thể Androgen, cũng như sự kết hợp của nó với ER. Vì vậy, chúng tôi chọn đề tài này với mục tiêu: Nhận xét một số mối liên quan giứa sự bộc lộ $A R, E R$ với typ phân tứ, NPI, nhóm nguy cơ và giai đoạn sau mô của ung thư vú.

\section{II. ĐỐI TƯợNG VÀ PHƯƠNG PHÁP NGHIÊN CỨU}

Đối tượng nghiên cứu: gồm 94 bệnh nhân ung thư biểu mô tuyến vú được phẫu thuật điều trị tại bệnh viện K năm 2014.

III. KẾT QUẢ NGHIÊN CỨU

Bảng 1. Sự bộc lộ của dâu ấn AR và ER

\section{Tiêu chuẩn lựa chọn đối tượng}

- Bệnh nhân được mổ cắt tuyển vú và không điều trị hóa chất và xạ trị tiền phẫu.

- Được chẩn đoán là ung thư biểu mô xâm nhập, nến đủ để nhuộm HMMD.

Tiêu chuẩn loại trừ: các trường hợp không đáp ứng đủ tiêu chuẩn trên và

- Ung thư vú tái phát hoặc di căn từ nơi khác đến. Ung thư vú tại chỗ.

\section{Phương pháp nghiên cứu}

Thiết kế nghiên cứu: Nghiên cứu mô tả cắt ngang, hồi cứu

\section{Các thông tin cân thu thập}

*Giải phẫu bệnh: chỉ số NPI, giai đoạn u sau mổ

*Hóa mô miễn dịch: theo phương pháp $A B C$ tiêu chuẩn. $A R$ : nhuộm $\geq 1 \%$ nhân tế bào là dương tính. ER, PR: Đánh giá kết quả theo tiêu chuẩn của Allred. HER2 theo tiêu chuẩn của DAKO và Ki67 theo St Gallen 2013.

\section{Kiểm chứng dướng và kiểm chứng âm}

- Kiểm chứng dương:

+ ER, AR: Biểu mô tuyến vú lành.

- Kiểm chứng âm: Không phủ kháng thể thứ nhất vào tiêu bản đối với tất cả các trường hợp nhuộm tiêu bản chứng âm.

*Tính chỉ số tiên lượng Nottingham (NPI), phân tầng nguy cơ theo St Gallen 2007 và chia typ phân tử theo bảng phân loại của St Gallen 2013.

Xử lý số liệu: Xử lý số liệu bằng phần mềm SPSS 16.

\begin{tabular}{|c|c|c|c|c|c|c|c|}
\hline & \multicolumn{4}{|c|}{ ER } & \multicolumn{2}{|c|}{ Tống } \\
\hline & & \multicolumn{2}{|c|}{ Äm tính } & \multicolumn{2}{|c|}{ Dương tính } & \multirow[b]{2}{*}{$\mathbf{n}$} & \multirow{2}{*}{$\%$} \\
\hline & & $\mathbf{n}$ & $\%$ & $\mathbf{n}$ & $\%$ & & \\
\hline \multirow{2}{*}{ AR } & Âm tính & 34 & 36,2 & 15 & 15,9 & 49 & 52,1 \\
\hline & Dương tính & 28 & 29,8 & 17 & 18,1 & 45 & 47,9 \\
\hline & Tổng & 62 & 65,9 & 32 & 34,1 & \multicolumn{2}{|c|}{94} \\
\hline
\end{tabular}

Nhận xét: Tỷ lệ AR-ER- cao nhất 36,2\%, tiếp đến là tỷ lệ AR+ER-: 29,8\%; thứ 3 là tỷ lệ đồng bộc lộ $A R+E R+: 18,1 \%$ và thấp nhất là tỷ lệ $A R-E R+: 15,9 \%$. Sự khác biệt không có ý nghĩa thống kề với $p>0.05(p=0,142)$.

Bảng 2. Sự bộc lộ AR, ER theo typ phân tü

\begin{tabular}{|c|c|c|c|c|c|c|c|c|c|c|}
\hline & \multicolumn{2}{|c|}{ AR-ER- } & \multicolumn{2}{c|}{ AR-ER+ } & \multicolumn{2}{c|}{ AR+ER- } & \multicolumn{2}{c|}{ AR+ER+ } & \multicolumn{2}{c|}{ Tống } \\
\cline { 2 - 11 } & $\mathbf{n}$ & $\mathbf{\%}$ & $\mathbf{n}$ & $\mathbf{\%}$ & $\mathbf{n}$ & $\mathbf{\%}$ & $\mathbf{n}$ & $\mathbf{\%}$ & $\mathrm{N}$ & $\%$ \\
\hline LUMA & 1 & 2,9 & 3 & 20,0 & 0 & 0,0 & 10 & 35,7 & 14 & 14,9 \\
\hline BH- & 0 & 0,0 & 8 & 53,3 & 2 & 11,8 & 15 & 53,6 & 25 & 26,6 \\
\hline BH+ & 0 & 0,0 & 4 & 26,7 & 0 & 0,0 & 3 & 10,7 & 7 & 7,4 \\
\hline HER2 & 19 & 55,9 & 0 & 0,0 & 6 & 35,3 & 0 & 0,0 & 25 & 26,6 \\
\hline BL & 14 & 41,2 & 0 & 0,0 & 9 & 52,9 & 0 & 0,0 & 23 & 24,5 \\
\hline Tống & 34 & 36,2 & 15 & 15,9 & 17 & 18,1 & 28 & 29,8 & \multicolumn{2}{|c|}{94} \\
\hline
\end{tabular}

Nhận xét: Ớ ung thư vú typ lòng ống $A$ (LUMA), kiểu hình miễn dịch AR+ER+ chiếm tỷ lệ cao nhất so với các nhóm khác, lần lượt là $35,7 \%$. Trái lại, kiểu hình miến dịch này và nhóm $A R-E R+$ 
không gặp trường hợp nào ở nhóm HER2 và dạng đáy $(B L)$. Ở typ phân tử HER2, nhóm AR-ERchiếm tỳ lệ cao nhất $(55,9 \%)$ và ung thư vú dạng đáy, kiểu hình AR+ER- chiếm tỷ lệ phổ biến nhất là $52,9 \%$.

Bảng 3. Sứ bộc lọ AR, ER theo NPI

\begin{tabular}{|c|c|c|c|c|c|c|c|c|c|c|}
\hline \multirow{2}{*}{ NPI } & \multicolumn{2}{|c|}{ AR-ER- } & \multicolumn{2}{c|}{ AR-ER+ } & \multicolumn{2}{c|}{ AR+ER- } & \multicolumn{2}{c|}{ AR+ER+ } & \multicolumn{2}{c|}{ Tống } \\
\cline { 2 - 11 } & $\mathbf{n}$ & $\mathbf{\%}$ & $\mathbf{n}$ & $\mathbf{\%}$ & $\mathbf{n}$ & $\mathbf{\%}$ & $\mathbf{n}$ & $\mathbf{\%}$ & $\mathrm{N}$ & $\%$ \\
\hline Tốt & 1 & 3,0 & 3 & 20,0 & 3 & 17,7 & 8 & 28,6 & 15 & 16,0 \\
\hline Trung bình & 15 & 44,1 & 8 & 53,3 & 9 & 52,9 & 16 & 57,1 & 48 & 51,1 \\
\hline Xấu & 18 & 52,9 & 4 & 26,7 & 5 & 29,4 & 4 & 14,3 & 31 & 32,9 \\
\hline Tổng & 34 & 36,2 & 15 & 15,9 & 17 & 18,1 & 28 & 29,8 & \multicolumn{2}{|c|}{94} \\
\hline
\end{tabular}

Nhận xét: Ơ ung thư vú NPI tốt và trung bình, kiểu hình miễn dịch $A R+E R+$ chiếm tỷ lệ cao nhất so với các nhóm khác, lần lượt là 28,6 và $57,1 \%$. Trái lại, kiểu hình miễn dịch này lại chiếm tỷ lệ thấp nhất ở NPI xấu (14,3\%) và AR-ER- chiếm tỷ lệ cao nhất ở ung thư vú NPI xấu $(52,9 \%)$.

Bảng 4. Sự bộc lộ AR, ER theo phân tầng nguy cơ

\begin{tabular}{|c|c|c|c|c|c|c|c|c|c|c|}
\hline \multirow{2}{*}{ Nguy cơ } & \multicolumn{2}{|c|}{ AR-ER- } & \multicolumn{2}{c|}{ AR-ER+ } & \multicolumn{2}{c|}{ AR+ER- } & \multicolumn{2}{c|}{ AR+ER+ } & \multicolumn{2}{c|}{ Tống } \\
\cline { 2 - 11 } & $\mathbf{n}$ & $\mathbf{\%}$ & $\mathbf{n}$ & $\mathbf{\%}$ & $\mathbf{n}$ & $\mathbf{\%}$ & $\mathbf{n}$ & $\mathbf{\%}$ & $\mathbf{N}$ & $\%$ \\
\hline Thấp & 1 & 3,0 & 1 & 6,7 & 0 & & 3 & 10,7 & 5 & 5,4 \\
\hline Trung bình & 13 & 38,2 & 11 & 73,3 & 11 & 64,7 & 22 & 78,6 & 57 & 60,6 \\
\hline Cao & 20 & 58,8 & 3 & 20,0 & 6 & 35,3 & 3 & 10,7 & 32 & 34,0 \\
\hline Tổng & 34 & 36,2 & 15 & 15,9 & 17 & 18,1 & 28 & 29,8 & \multicolumn{2}{|c|}{94} \\
\hline
\end{tabular}

Nhận xét: Ớ ung thư vú nguy cơ cao và trung bình, kiểu hình miễn dịch $A R+E R+$ chiếm tỷ lệ cao nhất so với các nhóm khác, lần lượt là 10,7 và $78,6 \%$. Trái lại, kiểu hình miễn dịch này lại chiếm tỷ lệ thấp nhất ở nhóm nguy cơ xấu $(10,7 \%)$ và AR-ER- chiếm tỳ lệ cao nhất ở ung thư vú nguy cơ xấu $(58,8 \%)$.

Bảng 5. Sự bộc lộ AR, ER theo giai đoạn sau mổ

\begin{tabular}{|c|c|c|c|c|c|c|c|c|c|c|}
\hline \multirow{2}{*}{$\begin{array}{c}\text { Giai } \\
\text { đoạn }\end{array}$} & \multicolumn{2}{|c|}{ AR-ER- } & \multicolumn{2}{c|}{ AR-ER+ } & \multicolumn{2}{c|}{ AR+ER- } & \multicolumn{2}{c|}{ AR+ER+ } & \multicolumn{2}{c|}{ Tống } \\
\hline I & $\mathbf{\%}$ & $\mathbf{n}$ & $\mathbf{\%}$ & $\mathbf{n}$ & $\mathbf{\%}$ & $\mathbf{n}$ & $\mathbf{\%}$ & $\mathbf{N}$ & $\%$ \\
\hline II & 2 & 5,9 & 6 & 40,0 & 1 & 5,9 & 6 & 21,5 & 15 & 16,0 \\
\hline III & 23 & 67,6 & 7 & 46,7 & 12 & 70,6 & 17 & 60,7 & 59 & 62,7 \\
\hline Tống & 3 & 26,5 & 2 & 13,3 & 4 & 23,5 & 5 & 17,8 & 20 & 21,3 \\
\hline
\end{tabular}

Nhận xét: Các kiểu hình miễn dịch $A R$, ER đều có tỷ lệ cao nhất ở giai đoạn II, nhất là AR+ER$(70,6 \%)$. Ở ung thư vú giai đoạn III, nhóm AR-ER- và AR+ER- đều chiếm tỷ lệ cao hơn giai đoạn I (lần lượt là 26,5 vs $5,9 \%$ và 23,5 vs $5,9 \%$ ), trong khi đó ở giai đoạn $I$, nhóm $A R-E R+$ và $A R+E R+$ đều chiếm tỷ lệ cao hơn giai đoạn III (lần lượt là 40,0 vs $13,3 \%$ và 29,8 vs $21,5 \%$ ).

\section{BÀN LUẬN}

AR được bộc lộ ở $90 \%$ ung thư vú ER dương tính và sự bộc lộ của nó có liên quan đến tiên lượng thuận lợi. Trong thứ nhóm của khối u này, AR dường như để ức chế sự tăng sinh tế bào do estradiol gây ra và có giá trị tiên lượng thuận lợi. $A R$ có thể điều chỉnh tín hiệu ER bằng cách can thiệp vào cả các hoạt động bộ của gen và không bộ gen. AR là một yếu tố phiên mã liên kết các AREs cụ thể trên DNA. Ở trạng thái không hoạt động, $A R$ nằm trong tế bào chất và là liên kết với protein sốc nhiệt (HSP) 70 và 90 . Khi androgen được hoạt hóa, $A R$ được giải phóng bởi HSP và chuyển vào nhân, nơi nó nhận ra và điều hòa các gen đáp ứng androgen [6]. Trong $\mathrm{BC}$ dương tính với $E R, A R$ có thể can thiệp vào việc phiên mã phụ thuộc ER bằng cách cạnh tranh để gắn vào vị trí tương ứng hoặc tạo điều kiện cho ER gắn với $D N A$. Trong tế bào ung thư vú $E R+$ và PR dương tính, tín hiệu $A R$ có tác dụng ức chế sự phát triển của tế bào. Trong các tế bào này, $A R$ liên kết với phối tử di chuyển vào nhân và liên kết với $E R E$, cạnh tranh với $E R$ và $P R$. Trong tế bào ung thư có $P R$ âm tính, $A R$ có vai trò tiền tạo u và làm tăng phiên mã gen ER. AR cũng có thể điều chỉnh các hoạt động phi bộ gen được điều chỉnh bởi $E R$. Bất kể cơ chế nào, $A R$ kích thích hoặc ức chế sự tăng sinh tế bào, thúc đẩy quá trình di căn hoặc kháng lại các liệu pháp trong tế bào ung thư vú dương tính với $E R$. Những hành động đối lập có thể phụ thuộc vào vô số các protein tương tác với $A R$. AR được biểu hiện trong 70-95\% ung thư vú ER+. AR đã được ghi nhận là có tương quan với các kết quả thuận lợi như kích thước khối u nhỏ hơn, khối u thấp hơn, ít hoại tử hơn, mức Ki-67 thấp hơn và đáp 
ứng điều trị tốt hơn trong ung thư vú ER+ [7]. Gần đây, một nghiên cứu lớn bao gồm 4.147 phụ nữ trước và sau mãn kinh với $\mathrm{BC}$ xâm lấn cho thấy biểu hiện $A R$, độc lập với các đặc điểm GPB lâm sàng, có liên quan tới sựcải thiện tỷ lệ sống sót của bệnh nhân ung thư vú có $E R+$ trong 5-10 năm đầu sau chẩn đoán. Một nghiên cứu cho thấy $A R$ cao mức ở ung thư vú $E R+$ tương quan với ít thâm nhiễm tế bào lympho $u$ và hoạt động phân giải tế bào hơn, cũng như độ kém nhạy hơn nhiều với hóa trị liệu tân bổ trợ, nhưng khả năng sống sót tốt hơn [8]. Tuy nhiên, một nghiên cứu trên 3.021 phụ nữ sau mãn kinh $\mathrm{BC}$ có $\mathrm{ER}$ + giai đoạn đầu cho thấy rằng biểu thức AR không được liên kết với tiên lượng, cũng như không thể dự đoán đáp ứng với letrozole hoặc tamoxifen. Ngược lại, tỷ lệ AR / ER đã được coi là ảnh hưởng đến tiền lượng và đáp ứng với liệu pháp nội tiết kháng estrogen. Cochrane và cộng sự tiết lộ rằng bệnh nhân ung thư vú ER + với tỷ lệ $A R / E R>2$, tăng gấp 4 lần nguy cơ thất bại với tamoxifen trị liệu.

Trong $\mathrm{n}$ ghiên cứu của chúng tôi (bảng 1), đánh giá sự bộc lộ 2 dấu ấn $A R$ và $E R$ để xác định các kiểu hình miễn dịch của ung thư vú cho thấy tỷ lệ AR-ER- cao nhất 36,2\%, tiếp đến là tỷ lệ $A R+E R-:$ 29,8\%; thứ 3 là tỷ lệ đồng bộc lộ $A R+E R+: 18,1 \%$ và thấp nhất là tỷ lệ $A R-E R+:$ $15,9 \%$. Khi đánh giá các kiểu hình miễn dịch này với các đặc điểm GPB: typ phân tử, NPI, nhóm nguy cơ, giai đoạn sau mổ của ung thư vú cho thấy có sự khác nhau giữa các kiểu hình miễn dịch này.

Ung thư vú đã được phân loại ít nhất thành 5 typ chính chúng khác nhau rõ rệt về chủng tộc/sắc tộc riêng biệt, phân bố các yếu tố nguy cớ, tiên lượng, đáp ứng với liệu pháp điều trị,, kết quả lâm sàng và cả thời gian sống thêm toàn bộ và thời gian sống thêm không bệnh. Các typ phân tử này có các đặc điểm riêng biệt, giống như các typ được xác định bằng phân tích gen, bao gồm kết quả lâm sàng rõ ràng, mức độ đáp ứng với điều trị bổ trợ khác nhau và tỷ lệ di căn, tái phát khác nhau. Ở bảng 2 cho thấy, trong ung thư vú typ lòng ống $A$ (LUMA), kiểu hình miển dịch $A R+E R+$ chiếm tỷ lệ cao nhất so với các nhóm khác, lần lượt là 35,7\%. Trái lại, kiểu hình miễn dịch này và nhóm $A R-E R+$ không gặp trường hợp nào ở nhóm HER2 và dạng đáy $(\mathrm{BL})$. Ở typ phân tử HER2, nhóm AR-ER- chiếm tỷ lệ cao nhất $(55,9 \%)$ và ung thư vú dạng đáy, kiều hình AR+ER- chiếm tỷ lệ phổ biến nhất là 52,9\%.

Dựa vào kích thước $u$, tình trạng hạch và độ mô học là những yếu tố quan trọng nhất. Dựa vào các mức điểm ung thư vú được chia thành 3 mức độ tiên lượng: tốt, trung bình và xấu. Chỉ số NPI có ưu thế đáng kể về tính đơn giản, dễ áp dụng trong hoàn cảnh cần phải tìm kiếm các yếu tố khách quan hơn có thể phản ánh tính chất sinh học riêng biệt của các ung thư vú, chính xác hơn so với chỉ dựa vào hình thái học đơn thuần của u. Sự phân nhóm tiên lượng tốt hơn sẽ giúp bệnh nhần được điều trị ở giai đoạn sớm hơn, đồng thời tránh cho họ các nguy cơ phải nhận các điều trị hỗ trợ không cần thiết. Trong nghiển cứu của chúng tồi (bảng 3) cho thấy ở ung thư vú NPI tốt và trung bình, kiểu hình miễn dịch $A R+E R+$ chiếm tỷ lệ cao nhất so với các nhóm khác, lần lượt là 28,6 và $57,1 \%$. Trái lại, kiểu hình miễn dịch này lại chiếm tỷ lệ thấp nhất ở NPI xấu $(14,3 \%)$ và $A R-E R-$ chiếm tỷ lệ cao nhất ở ung thư vú NPI xấu $(52,9 \%)$.

Các yếu tố tiên lượng quan trọng nhất cho bệnh nhân ung thư vú là có hay không có di căn hạch nách. Hơn nữa, có mối liên quan trực tiếp giữa số lượng nách bị di căn và nguy cơ di căn xa, vì vậy bệnh nhân chưa di căn hạch là những bệnh nhân bị bệnh có nguy cơ thấp. Theo hội nghị đồng thuận St Gallen, Thụy Sĩ-2005 và năm 2007 bổ sung nhóm có nguy cơ trung gian, vì bệnh nhân có di căn hạch nách nhưng không có đặc điểm nguy cơ cao nào khác sẽ được xếp vào nhóm bệnh có nguy cơ cao. Các yếu tố tiên lượng mới khác cũng là chấp nhận: bộc lộ quá mức HER2, ĐMH, kích thước u, xầm nhập mạch quanh u và tuổi của bệnh nhân. Kết hợp các yếu tố này có thể chia bệnh nhân ung thư vú trong ba loại nguy cơ: thẩp, trung và cao. Theo sự phân nhóm này có thể lựa chọn đúng chiến lược điều trị cho bệnh nhân. Qua đánh giá kiểu hình miễn dịch $A R$, ER với các nhóm nguy cơ, bảng 4 cho thấy ở ung thư vú nguy cơ cao và trung bình, kiểu hình miễn dịch $A R+E R+$ chiếm tỷ lệ cao nhất so với các nhóm khác, lần lượt là 10,7 và $78,6 \%$. Trái lại, kiểu hình miễn dịch này lại chiếm tỷ lệ thấp nhất ở nhóm nguy cơ xấu $(10,7 \%)$ và $A R-E R-$ chiếm tỷ lệ cao nhất ở ung thư vú nguy cơ xấu $(58,8 \%)$.

Giai đoạn của ung thư vú là yếu tố tiên lượng quan trọng liên quan đến tỷ lệ sống thêm và phương pháp điều trị. Ung thư vú đươơc chia làm 4 giai đoạn dựa trên phạm vi giải phẫu của tổn thương. Giai đoạn sau mổ cung cấp thêm những thông tin chính xác hơn dựa trên bệnh phẩm sau mổ giúp cho điêu trị bố trợ tiếp theo. Trong nghiên cứu của chúng tôi cho thây (bảng 5) Các kiểu hình miễn dịch $A R$, $E R$ đều có tỷ lệ cao nhất ở giai đoạn II, nhất là AR+ER- (70,6\%). Ở ung 
thư vú giai đoan III, nhóm $A R-E R-$ và $A R+E R-$ đều chiếm tỷ lệ cao hơn giai đoạn I (lần lượt là $26,5$ vs $5,9 \%$ và 23,5 vs $5,9 \%)$, trong khi đó ở giai đoan $I$, nhóm $A R-E R+$ và $A R+E R+$ đều chiếm tỷ lê cao hơn giai đoan III (lần lượt là 40,0 vs $13,3 \%$ và 29,8 vs $21,5 \%$ ).

\section{KẾT LUÂ̂N}

Ung thư vú có kiểu hình miễn dich $A R+E R+$ thường kết hợp với các đặc điểm giải phẫu bệnh tốt nhất, trái ngược với kiểu hình miễn dịch ARER- thường có biểu hiện các đặc trưng giải phẫu bệnh xấu hơn.

\section{TÀI LIÊU THAM KHẢO}

1. Peters AA, Buchanan G, Ricciardelli $C$, Bianco-Miotto T, Centenera MM, Harris JM, et al. Androgen receptor inhibits estrogen receptor-alpha activity and is prognostic in breast cancer. Cancer Res. (2009) 69:6131-40. doi: 10.1158/0008-5472.CAN-09-0452.

2. Vasiliou SK, Diamandis EP. Androgen receptor: a promising therapeutic target in breast cancer. Crit Rev Clin Lab Sci. (2019) 56:200-23. doi: 10.1080/10408363.2019.1575643.
3. Need EF, Selth LA, Harris TJ, Birrell SN, Tilley WD, Buchanan G. Research resource: interplay between the genomic and transcriptional networks of androgen receptor and estrogen receptor alpha in luminal breast cancer cells. Mol Endocrinol. (2012) 26:1941-52. doi: 10.1210/me.2011-1314.

4. Rahim B, O'Regan $R$. AR signaling in breast cancer. Cancers. (2017) 9:21. doi: 10.3390/ cancers9030021.

5. McNamara KM, Moore NL, Hickey TE, Sasano H, Tilley WD. Complexities of androgen receptor signalling in breast cancer. Endocr Relat Cancer. (2014) 21:T161-81. doi: 10.1530/ERC-14-0243.

6. Giovannelli $P$, Donato MD, Galasso G, Zazzo ED, Bilancio A, Migliaccio A. The Androgen Receptor in Breast Cancer. Front Endocrinol. 2018;9:492.

7. Anand A, Singh KR, Kumar S, Husain N, Kushwaha JK, Sonkar AA. Androgen Receptor Expression in an Indian Breast Cancer Cohort with Relation to Molecular Subtypes and Response to Neoadjuvant Chemotherapy -a Prospective Clinical Study. Breast Care. 2017;12:160-164.

8. Anestis A, Zoi I, Papavassiliou AG, Karamouzis MV. Androgen Receptor in Breast Cancer-Clinical and Preclinical Research Insights. Molecules. 2020;25:358.

\section{NGHIÊN CỨU ĐĂC ĐIỂM BIẾN THIÊN NHİP TIM Ở BÊNNH NHÂN TRƯớC VÀ SAU PHẪU THUÂTT CẦU NỐI CHỦ VÀNH}

\section{TÓM TẮT}

Sau phẫu thuâtt cầu nối chủ vành có hiện tượng giảm biển thiên nhịp tim. Đây được xem là một trong những dấu hiệu của rối loạn chức năng tim và̀ là một trong những yếu tố tiên lượng các biến cố tim mạch. Vì vậy, chúng tôi nghiên cứu đặ̆c điểm thay đổi biến thiên nhịp tim trước và sau phầu thuật cầu nối chủ vành bằng Holter điện tim để là̀m cở sở đánh giá, theo dõi biến cố tim mạch sau phẫu thuật. Đối tượng và phương pháp nghiên cứu: tiến cứu mô tả theo dõi dọc 119 bênh nhân được phẫu thuât cầu nối chủ vành có tuần hoàn ngoài cờ thể tại Bệnh viện Tim Hà Nội từ 6/2016 đến 8/2018. Theo dõi biến thiên nhịp tim bằng Holter điện tim 24 giờ tại các thời điểm trước phẩu thuât, sau phẫu thuật 7 ngày, 3 tháng và 6 tháng. Kềt quả: Tất cả các chỉ số biến thiên nhịp tim theo thời gian và theo phổ tân số đều giảm sau phẫu

${ }^{1}$ Bệnh viện Tim Hà Nội

ªênh viện 108

${ }^{3}$ Bệnh viện Bạch Mai

Chịu trách nhiệm chính: Ngọ Văn Thanh

Email: ngogiahung@gmail.com

Ngày nhận bài: 18.01.2021

Ngày phản biện khoa học: 15.3.2021

Ngày duyệt bài: 25.3.2021
Ngọ Văn Thanh', Phạm Trường Sơn ${ }^{2}$,
Nguyến Quang Tuấn ${ }^{3}$ và cs.

thuật, hâuu hết phục hồi sau 3 tháng. Đặc điểm biến thiên nhịp tim giảm trước phẫu thuật có tỉ lệ là $28,6 \%$, sau 7 ngày $51,8 \%$, sau 3 tháng $19,6 \%$ và sau 6 tháng là $12,7 \%$. Trong đó chỉ số ASDNN và SDNN trước và sau phẫu thuật có tỉ lệ thay đổi nhiều nhất. Kết luận: Các chỉ số biển thiên nhip tim theo phổ tần số và theo thời giañ thay đổi giảm, thấp nhất ở giai đoạn sớm sau phẫu thuật. Các chỉ số này hồi phục sau 3 tháng, tăng lên sau 6 tháng so với trước phâuu thuật.

Tư khoá: biến thiên nhịp tim, phẫu thuật câu nối chủ vành.

\section{SUMMARY}

\section{HEART RATE VARIABILITY IN CORONARY} ARTERY BYPASS GRAFTING PATIENTS

Introduction and objectives: The heart rate variability in the patients pre and postoperative CABG measured by Holter ECG 24 hours are marker of ventricular dysfunction and indicates a poor prognosis as major adverse cardiovascular events. Autonomic heart rate control is impaired after coronary artery bypass grafting. The aim of this study was to establish the temporal pattern of change in the decrease of heart rate variability observed after coronary artery bypass grafting. Methods: cross sectional description. The study involved 119 consecutive patients with coronary artery disease were assessed with 24-hour Holter recordings 2 days before coronary artery 